\title{
Requirements and system design for a robot performing selective cleaning in young forest stands
}

\author{
Karin Vestlund $^{\mathrm{a}, *}$, Thomas Hellström ${ }^{\mathrm{b}}$ \\ a Department of Silviculture, Swedish University of Agricultural Sciences, Box 7060, \\ 75007 Uppsala, Sweden \\ ${ }^{\mathrm{b}}$ Department of Computing Science, Umeå University, 90187 Umeå, Sweden
}

Available online 19 August 2005

\begin{abstract}
Cleaning is a silvicultural tending operation, primarily aimed at improving the growing conditions of the remaining trees in young stands (ca. $3 \mathrm{~m}$ of height). The cost of cleaning has increased in comparison to other forest operations, and the annually cleaned area has decreased in Sweden. Therefore, cleaning with robots might be the key to improve profitability. This paper aims at assessing some design requirements, and suggesting an architecture for a robot cleaning in young forest stands, based on reviewed literature and our own research. The results of cleaning performed by robots have to reach acceptable results and be done at a competitive cost. The robot has to find, select, and handle trees in the whole assigned area according to given instructions. Furthermore, it must be safe for humans, capable of moving safely within the forest environment, and be able to handle snow and other prevalent boreal weather conditions. The vehicle's size and mass are of importance, and bear on its ability to manoeuvre among remaining stems. Generally, the robot must be capable of operating independently and unattended for several hours in a dynamic and non-deterministic environment. Obstacle avoidance and target identification are identified as the most difficult problems. Machine vision, radar, and laser scanners are promising techniques for both obstacle avoid-
\end{abstract}

\footnotetext{
* Corresponding author.

E-mail addresses: karin.vestlund@ssko.slu.se (K. Vestlund), thomash@cs.umu.se (T. Hellström).
} 
ance, tree identification, and tool control. The proposed architecture is based on a hybrid between the reactive and the hierarchical robot paradigms.

(C) 2005 ISTVS. Published by Elsevier Ltd. All rights reserved.

Keywords: Forestry; Pre-commercial thinning; Off-road robot; Autonomous outdoor vehicle

\section{Introduction}

\subsection{Cleaning}

Cleaning (pre-commercial thinning) is a silvicultural tending operation. It is usually performed in stands of three metres of height $[63,5,54]$. Cleanings are primarily done to improve the growing conditions of the remaining stems, i.e., main-stems, for instance by increasing the volume growth per stem and decreasing the likelihood of damage [6]. A main-stem is a tree selected to remain in a stand, because it is deemed good quality, i.e., straight, vigorous, undamaged, etc. (e.g., Karlsson et al. [42]), or at least better than surrounding stems. Cleaning operations can be selective, geometrical, or a combination of both [10]. In selective cleaning, in contrast to geometrical cleaning, the main-stems are chosen individually (cf. Vestlund [75]). The reasons for making individual selections are usually the desire to enhance the stand quality and/or to influence species composition (e.g., Berg et al. [10]). Selective cleaning, hereafter denoted cleaning, is predominant in Sweden and Finland, whereas geometrical cleaning is used in Canada for example [67], and for beech stands in southern Sweden and Denmark.

In Sweden, almost all cleaning is currently done motor-manually with brush-saws, and the cleaned area in 2001 amounted to 253,600 hectares [9]. The cost of cleaning compared to logging and scarification costs has increased during the last twenty years (cf. Anon [4], Vestlund [75], Anon [9]). The annually cleaned area has decreased over the last decade, and the number of remaining stems in individual stands has increased $[63,9]$. This trend indicates that there is not enough willingness to pay the actual cost of cleaning. Furthermore, motor-manual work is laborious, which might be one reason for the difficulties in finding cleaners [76]. In Canada too, there are concerns about lack of cleaners and that the costs of cleaning might rise [7]. Therefore, there seems to be a need for new techniques to make future cleaning less expensive and reduce the human workload. Cleaning with autonomous artificial agents (robots) may be a way to solve the laborious working conditions, and decrease the costs. The word autonomous derives from the Greek word autonomos (auto + nomos), which means living under one's own law [3]. It means being independent of other things, while acting or being able to act in accordance with rules and principles of one's own choosing. An autonomous robot can adapt to changes in its environment or in itself, and proceed to reach its goals.

\subsection{Previous work: mechanisation and automation}

Attempts to mechanise cleaning started in Sweden in the 1970s. In the late 1980s and beginning of 1990 s some cleaning in industrial forests were performed mechan- 
ically [75]. However, no more than 20 machines were said to be in use annually during these years $[51,75]$. The total economy for the machines was poor, and it became easier to find workers to perform the cleaning. These were the reasons for today's negligible amount of mechanical cleaning [46]. This is in spite of Lindman's [48] findings that mechanical cleaning was cheaper than motor-manual cleaning in stands with more than 10,000 stems per hectare before cleaning.

Autonomous land vehicles, denoted ALV, have been an intense area of research and development for the last decades all over the world. Nowadays autonomous and semi-autonomous vehicles are used for production in a number of areas, such as mining, transportation of goods, and agriculture. An introduction and summary of the state-of-the-art in the field is given in Durrant-Whyte [18]. Examples of successful projects in application areas that relate to agriculture and forestry are listed below.

\subsubsection{Agricultural vehicles}

Extensive research and development with autonomous vehicles for use in agriculture have been conducted the last decades. The primary agricultural activities addressed were harvesting, mowing, and applications of pesticides.

- O’Connor et al. [57] developed, at Stanford University, a system for agricultural equipment that follows a pre-planned path. A four-antenna system with differential GPS (DGPS) provided a heading accuracy of $0.1^{\circ}$ and offset accuracy of $2.5 \mathrm{~cm}$.

- A row-following system (using odometry and machine vision) for harvesting in cauliflower fields was developed by Marchant et al. [49].

- At Carnegie-Mellon Robotics Institute, an autonomous vehicle for cutting forage using vision-based perception on the cut and uncut regions of crop was developed $[59,60]$.

- Noguchi et al. [53] combined computer vision with fuzzy logic, genetic algorithms, and neural networks in a system for "smart spraying" for weed control and detecting crop growth.

- Zhang et al. [79] describes a project involving fusion of computer vision, kinematics GPS, and a fibre optic gyroscope (FOG). The techniques are used to guide an agricultural vehicle following crop rows. The reason of using sensor fusion is to combine the advantages of the different sensor types, while avoiding their drawbacks. GPS is said to be affected by reflections from trees and obstructions, computer vision is affected by soil colour and changing light levels, while the FOG is subject to drifting errors. By combining the three sensor types, a better performing system was achieved.

- A development project for an Autonomous Christmas Tree Weeder is described in a feasibility report [36]. The goal is to develop a light Christmas tree weeder, which is "superior to the present heavy ineffective, costly, and environmental detrimental equipment, and can make mechanical weed control competitive to chemical control". 


\subsubsection{Forest vehicles}

- A project for developing robots for cleaning (weeding, brushing and thinning in young coniferous stands) started in 1993 in Canada. In this project, some prototypes were built, designed to develop and demonstrate autonomous control, to study forest environment sensing, and to test mobility concepts. This project ended in 1995 [43].

- A tracked robot for bush removal between desired trees in steep terrain is being developed in Japan [44]. The desired trees are identified by IDC (Intelligent Data Carrier tags).

- The project Autonomous Navigation for Forest Machines started in 2002 at Umeå University, Sweden. This project is a part of a long-term vision to develop an unmanned vehicle that transports timber from the area of felling to the roadside, and addresses the problems with localisation and obstacle avoidance in forest terrain [38].

Safety is often believed to be the hardest problem in developing automated unmanned vehicles $[66,70]$. The problems to be addressed involve avoidance of human injury and damage to vehicles and environment. Reid [66] reports that mental barriers against the development of autonomous machinery already (1996) exist in some places in the USA, due to poor decisions made in the operation of equipment in the agricultural sector. One way of addressing the security issue is to design the vehicle to pause and call for operator assistance when uncertain situations are encountered.

The state-of-the-art in ALV provides the necessary technology to develop working systems in numerous application areas. Durrant-Whyte [18] summarises the situation: "... the necessary sensors, algorithms, and methods to develop and demonstrate an operationally viable all-terrain ALV already exist and could be readily deployed... the successful development of an operational ALV system will rely on an effective approach to systems engineering." However, the fact that to our knowledge no commercially available industrial product exists, indicates that the way to achieve a fully operational ALV for commercial forest applications is both long and challenging. To be able to have a useful platform for forestry, there is a need to define the special requirements of this environment.

The economy would benefit by the robot being able to carry different tools. Standard spare parts and easy maintenance, for the vehicle as well as for hardware and software components, is also of importance. The vehicle will probably be quite expensive and work unattended for long periods, which makes it exposed to theft. Blackmore et al. [14] discuss this problem and suggest that the robot should transmit an alarm signal if moved when the engines are not running.

\subsection{Aim}

This paper aims at assessing forestry requirements, reviewing available technology, and suggesting a system design for a robot performing selective cleaning in young forest stands. The forestry requirements are mainly derived from a Nordic 
point of view. The work is based on reviewed literature and our previous research in the area $[75,38]$.

An analysis of operational requirements for a cleaning robot from the forestry and stakeholders point of view is presented in Section 2, followed by a specification of general requirements in Section 3. Section 4 contains an overview of technical solutions suitable for the task. A proposed system design is presented in Section 5. Section 6 concludes the paper with general remarks and suggestions for future work.

\section{Operational requirements}

\subsection{Work performance}

The cleaning performance of a robot must achieve results considered acceptable by the landowners. This implies that a robot must be able to identify trees and the characteristics that indicate whether a tree should be selected as a main-stem, or be cut off. Interesting characteristics are species, straightness, vigour, degree of damage, branch structure, etc. (e.g., Karlsson et al. [42]). Usually, for Scots pine and Norway spruce stands in Sweden the recommendation, depending on site quality and species, is to leave between 1400 and 4000 stems per hectare, when cleaning stands of which the average height is three meters (e.g., Pettersson and Bäcke [63], Anon [5], Normark and Bergqvist [54]). Damaged stems (e.g., crooks, top failure, spike knot, bark loss), stems of undesired species, small stems, and too large stems with thick branches are usually undesirable and should be cut, provided that surrounding trees are better $[15,42,5,54]$. However, the distance between two trees after cleaning should not exceed twice the recommended spacing [15]. This means that less desirable trees sometimes must be accepted as main-stems to avoid creating gaps in the stand [42]. The selections of main-stems are based on both quality criteria and relative positions, which makes the decision process complex. Moreover, desirable trees should not be removed simply for the purpose of creating a more uniform stand [42]. The minimum allowed distance between two main-stems ranges from 0.6 to $1.0 \mathrm{~m}$ according to different cleaning manuals $[15,5,54]$. However, these instructions are not uniform and may change in the future, as they have in the past (e.g., Söderström [72]). This implies that the robot must be able to adapt to varying instructions. A training interface is required, e.g., when changing the desirable characteristics of the main-stems.

With a density of 1400 trees per ha the spacing is $2.67 \mathrm{~m}$. This means that to avoid gaps, robots should identify stems within a radius of approximately $5 \mathrm{~m}$ (Fig. 1). To reach the density goal the robot must keep track of the current number of trees selected as main-stems and their species. Brunberg [15] suggests that cleaners should focus on the main-stems and then cut the other ones. This approach seems useful also for automatic cleaning. Furthermore, the robot must have the capability to conclude that the cleaning has been accomplished, both around the main-stems and in the whole stand.

The robot must be able to cut undesired trees. The stump diameter of a tree in a traditional Swedish cleaning stand is usually less than $15 \mathrm{~cm}$, and its height is less 


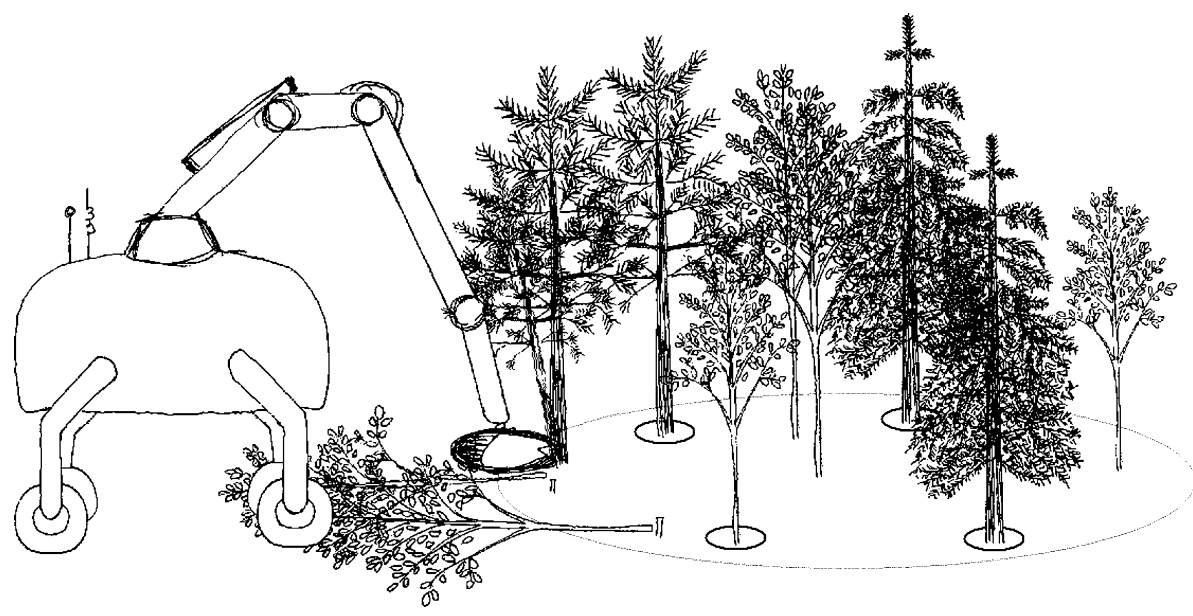

Fig. 1. An illustration of a robot cleaning in a young forest (the four trees with circles are selected mainstems, other trees are to be cut).

than $10 \mathrm{~m}$ (cf. Gustavsson [30]). In a study about stands considered for cleaning the highest tree was $8.0 \mathrm{~m}$ and the largest diameter $12.6 \mathrm{~cm}$ at stump height [75]. Gustavsson [30] found that $99 \%$ of the trees in a stand with an average height of $6.0 \mathrm{~m}$ had a mass less than $98 \mathrm{~kg}$, and with average height of $3.6 \mathrm{~m}$ less than $35 \mathrm{~kg}$. When considering the study by Vestlund [75] it can be assumed that the expected mass of the trees is below $100 \mathrm{~kg}$.

A robot must be capable of removing competing vegetation without damaging the selected main-stems. Eickhoff [19] found that $2 \%$ of the trees were damaged in motor-manual and 4-8\% in mechanised cleaning. About half the damage done in the mechanised case was caused by the tyres, $30-40 \%$ by the tool, and the remaining part by straddling. The acceptable damage frequency in Swedish thinning was to be below $5 \%$ [2]. Thinning is a similar procedure to cleaning, but thinning is done in older stands, and removed trees are used commercially for pulp or in sawmills. This damage level is still used in practical judgments. Ideally, no main-stem should be damaged, but a more realistic aim is a damage frequency of less than $5 \%$. Damage at this level can be accepted, as further selections among the remaining stems are made during thinning sessions later in the rotation period.

According to Johansson [41] the radius free of competing vegetation around a main-stem should be at least $0.25 \mathrm{~m}$, and a coniferous main-stem should not have a deciduous stem within $0.5 \mathrm{~m}$. However, trees up to half of the mean height of the stand could be left untreated [15,42,54]. Research in stands with ca. 20,000 stems per hectare indicates that of all the stems within $1 \mathrm{~m}$ from a main-stem, $5 \%$ were closer than $20 \mathrm{~cm}$ [26]. Another, in stands with 7650-15,700 stems per hectare, showed that $13 \%$ of all stems had at least one other stem positioned within a $10-\mathrm{cm}$ radius [75]. This indicates that the accuracy of the cleaning tool must be around $10 \mathrm{~cm}$ in total for positioning and for keeping its position during the operation. 


\subsection{Forest environment}

The forest environment includes various kinds of potential hazards for a robot, for example stones, rocks, pits, wet areas, ravines [26,78]. In the winter thin ice, which does not support the mass of a robot, can be a problem [26]. A robot must be able to handle or avoid these obstacles. Traditional forest machines (e.g., harvester and forwarder) have propulsion difficulties in terrain where the ground strength, roughness, and slope are classified as '4' and ' 5 ' according to the Swedish Terrain Classification System [11]. It might be possible to build machines that can handle difficult terrain. However, there is no reason to demand more of a robot than of traditional small-scale forest machinery. Nordfjell [55] found that these machines can operate in areas where the ground strength class is ' 4 ' or half of class ' 5 ', in the better half of the areas with roughness class ' 3 ', and in areas with slope classified as ' 3 '. This renders $72-77 \%$ of the Swedish forest area, and approximately $62 \%$ in Norway operable $[1,55]$.

In many areas cleaning cannot be performed throughout the year (e.g., due to the risk of insect damage, stump sprouts from deciduous trees, snow, and severe cold). However, to be economical a robot should be able to work at all times and normal weather conditions. The robot must also be able to operate when the snow depth is less than approximately $50 \mathrm{~cm}$, as this would "normally" make half of Sweden accessible all year round [22]. Another problem can be cut trees blocking the path of the robot. A robot must be able to pass these cut stems, and also to push smaller untreated trees out of its way. Selected main-stems are also obstacles to be avoided.

\subsection{Size and mass}

A cleaning machine could either straddle the main-stems or pass between them. If the machine should straddle them, its ground clearance has to be half the tree height [37]. Since many areas in Sweden have problems with moose browsing, many pinestands are not cleaned before having reached 4-5 $\mathrm{m}$ [42]. Furthermore, straddling should preferably not be done in springtime, during the period of sap flow [62], or when the temperature is below $-15^{\circ} \mathrm{C}$ [20]. Therefore, a machine able to work between the remaining trees seems preferable.

A successful regeneration often results in numerous trees located in scarification and plantation rows [75]. The distance between these rows is usually in Sweden about $2-2.5 \mathrm{~m}$, as a consequence of the spacing recommended for planting [6]. To be able to work between the stems, a robot should be at least $0.2 \mathrm{~m}$ narrower than the distance between the stems [77], i.e., not more than $1.8 \mathrm{~m}$ wide. Soil compaction decreases tree growth and the ground pressure should therefore not exceed $70 \mathrm{kPa}$, i.e., a mass less than approximately $5000 \mathrm{~kg}$, depending on the tyre (or foot) dimension [40]. Consequently, the boom and cleaning tool cannot be too heavy. However, the boom must have the ability to perform cleaning around the main-stem. The size and mass are also of importance for the transportability between cleaning sites. 


\subsection{Safety}

In uncertain and insecure situations, the robot should stop, alert a human operator, and await manual assistance. For example, when an unauthorised human or an animal is present within a certain distance from the robot. However, the operator must be allowed to come closer to the robot within specified sectors during the cleaning operation and in cases of false alarm, and command the vehicle to resume the operation. An operator must also have the possibility to immediately stop the robot, and directly control e.g., boom, tool, and steering when required. For this purpose there is a need for tele-operation and an easy-to-use and understand man-machine interface.

\section{Requirements in general}

Based on the arguments in the previous section, the following list of requirements for a robot usable in cleanings can be established:

1. Work performance. Able to reach an acceptable cleaning result, i.e., identify and select main-stems, remove undesired stems without damaging the main-stems, adapt to different instructions, and treat the whole assigned area. This includes handling stems with a stump diameter up to $15 \mathrm{~cm}$, height up to $10 \mathrm{~m}$, and mass up to $100 \mathrm{~kg}$, as well as having a precision of about $10 \mathrm{~cm}$ when cutting a tree.

2. Mobility in forest environment. Able to move safely within the forest environment, and handle terrain with ground strength class ' 4 ', the better half of roughness class ' 3 ', and slope classified as ' 3 '. Handle snow depth below $50 \mathrm{~cm}$, and prevalent boreal weather conditions, excluding severe cold.

3. Size. Fit between plantation and scarification rows, i.e., less than $1.8 \mathrm{~m}$, and have a ground pressure less than $70 \mathrm{kPa}$, i.e., a mass approximately less than $5000 \mathrm{~kg}$.

4. Safety. Be safe for humans and for the operator, who must be able to tele-control the robot in certain situations.

Generally, the robot must have the ability to operate independently and unattended for stretches of several hours in a dynamic and non-deterministic environment.

\section{Technical solutions/design}

This section contains an overview of techniques necessary to fulfil the above-specified requirements.

\subsection{Sensor techniques for perception of environment}

Sensors for perception of the local environment, including obstacle detection, are machine vision, laser rangefinders, various kinds of radars, ultra sonic sensors, and 
infrared sensors, to name some examples. To be useable in a forest environment the sensors must tolerate outdoor conditions, e.g., natural light, shadows, fog, dust, rain, snow, and wind. They also have to be resistant to mechanical and thermal stress, see for example Löfgren et al. [45] for specifications. The sensors should be able to operate in normal boreal temperatures.

Machine vision (optical sensors) is described in Hague et al. [34] as a cheap, fast, and powerful sensing method. Still, it has its drawbacks, especially in an outdoor environment, where it has to handle natural lighting conditions. Direct sunlight, shadows, and clouds affect the observed data and artificial light creates shadows. Hague et al. [34] state other difficulties, such as storing and processing data, extracting useful information from the images, especially when dealing with natural objects. Dunn and Liang [17] present low-resolution vision modules for obstacle detection and avoidance. Ollis [58] and Pilarski et al. [64] use images to identify crop lines for an automated harvester. Since a robot usable in forestry also must work at night to be economical, artificial light may be needed. Kourtz [43] tested a variety of different light sources, which worked equally well.

Laser rangefinders have the great advantage of providing accurate depth information that has to be computed from calibrated stereo images, when cameras are used for the same task [68]. Laser rangefinders, also known as Ladar or Laser scanners, can be used to estimate the distance and heading to obstacles around the robot. Laser beams can be swept horizontally and/or vertically producing data, from which the distance to surrounding obstacles and targets can be calculated. Typical accuracy is $\pm 50 \mathrm{~mm}$ for single $180^{\circ}$ scan operations with a resolution of $0.5^{\circ}$. Total maximum range is between 50 and $150 \mathrm{~m}$. A more sophisticated kind of laser scanner can provide a 3D picture with depth information. Bergh et al. [12] describe the development of a compact, light, and low-power scanner, and how it can be used for navigation and 3D-mapping. A general problem with laser sensors is the sensitivity to dust, rain, and snow.

Millimetre wave radar promise performance, which is not degraded by outdoor conditions such as dust, rain, and snow $[71,69,8]$. The working method is comparable to laser range scanners, but radar is often considered a better alternative for the outdoor automation, since it also has the advantage of being able to descry information beyond light vegetation, such as bushes.

Ultrasonic sensors are common in indoor environments (using time-of-flight for a transmitted ultrasonic sound to detect objects in the surroundings), but have several drawbacks that make them unsuitable for outdoor applications. For example, most surfaces in an outdoor environment produce diffuse reflection, and in addition there are problems with air movements and ambient ultrasonic noise [34]. Ratner and McKerrow [65] managed to use continuous transmission frequency modulated ultrasonic sensors for successfully navigating along a concrete path in a park. However, the forest environment is much less structured and more variable than a park, and the usefulness of ultrasonic sensors under these conditions is questionable.

Passive infrared detectors can be used to detect human presence by sensing the heat radiating from the human body (cf. Tanaka et al. [73]). This heat is to a large extent located in a narrow frequency band, centred around $10 \mu \mathrm{m}$. Filtering 
techniques are used to build detectors triggering on this frequency band. In this way, many false alarms can be avoided.

If the vehicle's perception system functions properly, physically hitting an obstacle should not happen. However, since the vehicle does not operate in an ideal world, it is necessary to have physical switches along the rim of the vehicle, connected to the emergency stop of the vehicle, in such a way that they should cause the vehicle to halt immediately when activated (cf. Everett [23]).

The need for cost effective systems favours sensor types, which are (or will be) produced in large volumes, for example sensors developed in the multimedia and automotive industry [34]. A promising technique in this respect is the new generation of radars, being developed for collision avoidance in the automotive industry.

\subsection{Techniques for localisation}

Localisation involves sensing and/or computing the vehicle's pose (position and heading). In practice, many sensors are used simultaneously to determine the pose. Relative position, e.g., distance to a tree, is an extremely important function and has to be designed for high accuracy and reliable error detection. An extensive analysis of the area is given by Borenstein et al. [16]. The absolute position is only important when keeping the robot within the defined operating area, when the human operator has to find it, or when it is cooperating with other robots.

The basic techniques for localisations are GPS (Global Positioning Systems) possibly enhanced by sensor fusion with Inertial Navigation Systems, denoted INS, odometry, and compasses.

A GPS receiver delivers an estimate of the robot's position by measuring the difference between times-of-flight for signals from satellites. The velocity measurement accuracy is about $0.1 \mathrm{~m} / \mathrm{s}$. Basic GPS receivers have a position accuracy of around $5 \mathrm{~m}, 95 \%$ of the time. An extended technology is DGPS (differential GPS), which has an accuracy of around $0.5 \mathrm{~m}$ [18]. So-called real-time-kinematics-DGPS are capable of delivering a position with errors between 2 and $20 \mathrm{~cm}$, and a heading with an error of less than $0.1^{\circ}$ for a moving vehicle $[57,66]$. Regardless of the type of GPS, the technology has limitations that make it insufficient as a single position technique for an autonomous moving robot. Even under good conditions GPS routinely fails at times. However, these periods are most often short and a useful strategy for the presented project might simply be to halt operation until the GPS signal becomes reliable again [64]. A study by Gotthardsson [29] with GPS-receivers mounted on harvesters in northern Sweden (64th parallel) showed that few available satellites, high stand density, and pine stands (compared to spruce stands) had negative effect on the accuracy of the positioning data. At some hours of the day only four satellites were available for signal reception in this part of Sweden. The accuracy was also lower when standing still, since the position had a tendency to drift [29].

An INS, i.e., accelerometers integrated with gyroscopes, provides information about relative translations and rotations of the robot, without using any external 
sensor data. However, these inertial sensors drift with time, and accelerometers are sensitive to gravitational acceleration [34].

The steering angle and/or wheel rotation can be converted by the forward-kinematics equations to changes in orientation and position. This technique is called odometry, and it is extensively used in indoor robotics. Unfortunately, odometry is problematic in forest environment, since the terrain is uneven and ground humidity changes. This can cause slipping and sliding, which affect the measurements. It results in cumulative errors and positional drift. However, odometers and inertial systems are fairly reliable in the short term [34].

Compasses measure the orientation of the earth's magnetic field (most often only the horizontal component) relative to the vehicle. They are used to estimate the heading of the vehicle. Typical techniques are: gyrocompasses that use gyroscopes pointing towards the magnetic north pole, and flux-gate compasses that use a toroidal magnet suspended in the earth's magnetic field. This kind of sensor is highly susceptible to local variations in the ambient magnetic field [34]. Calibration is therefore essential. In addition, compasses are known to be of limited value close to large metal objects and machine equipment [34].

A common way to improve the localisation accuracy, is to combine different types of position sensors by sensor fusion. A common technique for this is Kalman filtering, which is a statistical method based on identification of the variance and covariance for the used sensors. Hassel and Hertzberg [35] combine a deterministic approach with Kalman filtering for sensor fusion of odometry and INS. This approach is reported to improve the position estimates significantly, compared to a pure Kalman filter approach.

In young dense forests, the trees often block the satellite signals. This can be overcome by combining GPS with an INS $[25,28]$. An agricultural vehicle for automated harvesting of alfalfa with a combined GPS, INS, and odometry is presented by Pilarski et al. [64]. The technique of stopping work until the GPS signal becomes reliable again is used by Pilarski et al. [64], and the typical lengths of dropouts were between 30 and $120 \mathrm{~s}$. For a test period of $13 \mathrm{~h}$, only five such dropouts occurred. The satellite geometry for GPS usage at high latitudes is unfavourable, and therefore these results are not necessarily generally valid. Furthermore, it is rather uncertain whether this method of simply stopping can be effective in highly dense forests, where the dropouts are caused by trees blocking satellite signals.

\subsection{Autonomous functions}

To identify stems, necessary criteria, measurable by a computer, must be defined. Today's cleaning manuals (e.g., Brunberg [15], Anon [5], Normark and Bergqvist [54]) are useful to "transform" selection rules so a computer can use them. However, other implicit requirements must also be identified.

Computer-based tree identification would benefit by previous knowledge about the trees and their environment. Useful data in the cleaning case are the variety of species that can be expected to be found (e.g., spruce, pine, and birch), the various characteristics for the species (e.g., shape, structure, habitat), as well as typical scenes 
in the terrain. In young forests, the view is usually severely restricted, and only parts of the trees are visible. Greater robustness is expected from a classification algorithm using both expected location of the main-stems, e.g., plantations rows, and their characteristics (cf. Hague et al. [34]). Many applications perform classification tasks with machine vision (e.g., Gerrish et al. [27]).

The position and characteristics of the main-stems are important. The locations of stems are initially unknown, and thus active short-range sensing becomes critical. Stereo cameras make it possible to compute distances to objects. However, stereovision requires carefully calibrated cameras. This is generally a demanding procedure requiring a lot of time and effort. Forsman [24] used cylinder approximations of mature trees as reference for viewpoint registration, linking 3D datasets into a map of the environment. Högström [39] used laser measurements to detect trees with a diameter of about $0.5 \mathrm{~m}$ at breast height. Högström [39] created a 2D diagram from the 3D dataset, and labelled the measurements within a vertical cylinder around the highest peaks in the $2 \mathrm{D}$ diagram. To find and locate trees, he tried to find the centre line of the tree, and by this process both position and diameter for these relatively large trees were identified. TarpJohansen [74] combined aerial photographs, $600 \mathrm{~m}$ above the forest, of an even-aged (74 years) oak stand, to obtain 3D maps of individual tree locations, and estimate the surface of each individual tree stem (parameterised by a cylinder), to facilitate the diameter estimation at breast height. In a stand of 60 trees, 56 were detected in five photos. The root mean square error for the diameter was $3.2 \mathrm{~cm}$. Stems in a cleaning stand were found with horizontal laser scanning. However, the measurements of their position, height, and diameter were not entirely accurate [21]. The height was underestimated, since the treetops were not found. The diameter for one stem was incorrect because not only the stem but the branches too were included in the calculations [21].

To be able to navigate autonomously the robot must sense and build a representation of its environment as well as locate itself. In an unstructured environment, like a forest, it is impossible to use a detailed a priori map. Yahja et al. [78] present a path planner navigating at two levels, local and global, using whatever available map for a global path planning in advance, and modifying the path on the local level as new map information is collected by the sensor system. Hague et al. [34] argue that it is difficult to develop a vision algorithm that enables interpretation of natural scenes reliably. They reckon that machine vision must be combined with other sensors to be used successfully by guided vehicles.

An operator may give instructions indicating where the machine should operate, and also provide a pre-planned preliminary path. As information is collected by the sensor system, the robot may modify the path to avoid obstacles, and to perform the cleaning over the whole designated area (cf. Blackmore et al. [14]). Hagras et al. [33] present an application for learning and adaptation by an autonomous outdoor agricultural mobile robot. In the experiments, which ran continuously for $4 \mathrm{~h}$ at different light and weather conditions, the robot was able to navigate and adapt to changes in ground conditions and robot kinematics, as well as to gather more experience. 


\subsection{Basic machine concept}

There is a number of commercialised forest machines that meet the size conditions; these machines are used, for example, by private forest owners (cf. Nordfjell [56]). Ligné et al. [47] present an interesting machine for mechanised stand-operating cleaning, i.e., working between the remaining trees. The machine is $1.6 \mathrm{~m}$ wide with a boom reach of $5 \mathrm{~m}$, the inner turning radius is $0.8 \mathrm{~m}$, and the mass is $2800 \mathrm{~kg}$ [47]. A robot working autonomously can be quite small, as there is no need for a cab. Taking into account the forces imposed by wind, rain, and snow, to be able to cut most of the trees, the robot must be capable of handling external forces of about $1000 \mathrm{~N}$ at the boom tip.

Today's forest machines can operate because they are powerful, have large wheels, and are controlled by experienced human operators, but they are expensive [43]. A robot might be equipped with legs. Legged propulsion has advantages in difficult terrain, and the impact on the ground is reduced by the omni-directional motion on soft terrain [31]. The foot, however, has to be able to adjust to the ground-carrying capacity and to slipping. A disadvantage of legged propulsion is the need for a highly advanced motion control system. Martins-Filho and Prajoux [50] present an application of rule-based reasoning to manage in real time the force distribution within a locomotion control of a four-legged walking robot. Other drawbacks with legged machines are the slow speed and inconvenience when the machine is towed. However, Halme et al. [32] have built a lightweight $(200 \mathrm{~kg})$ mobile service robot with wheels at the end of the legs; the wheels work as feet in the walking mode, and as wheels in the driving mode. It is fully acceptable for a robot usable in forestry to be quite slow, because it could work $24 \mathrm{~h}$ a day, the speed of a human in cleaning is around $1 \mathrm{~m} / \mathrm{s}$. A robot would probably not have to exceed that speed. However, the problems suggest that legged vehicles should be used only where they provide a significant advantage over other techniques, for instance in difficult terrain, or when the terrain is damaged by wheeled or tracked vehicles.

Gellerstedt et al. [26] argue that to increase cleaning productivity, it is more important to reduce the time of positioning the tool and the time of performing the cutting, than to get a faster machine speed or longer boom reach. A wide range of tools used for reducing competing vegetation is discussed in Ligné [46], where cutting is compared to other possibilities of reducing competing vegetation, e.g., steam, crushing, and breaking the stem. If the tree is to be cut off, shearing is preferred to sawing, due to the risks of thrown stones, etc. caused by a saw. A promising new patented type of cutting device is a tool that shears stems up to $12 \mathrm{~cm}$ at stump height, based on a cutting-squeezing technique [47]. This makes the whole machine require up to $18 \mathrm{~kW}$ [47], whereas a rotating tool may need some $40 \mathrm{~kW}$ to be efficient.

For good performance, the tool should automatically find its working position, and then be able to move in parallel to the ground. Gellerstedt et al. [26] argue that there should be a minimum allowed distance of about $10 \mathrm{~cm}$ between the tool and the stem surface to prevent damage to the stem. The tool should be able to handle stump diameter up to $15 \mathrm{~cm}$ and the cutting edge must be protected from damage and easy to maintain. If a rotating tool is used guards are required to prevent objects, such as tool parts, limbs, and stones from being thrown [26]. 


\subsection{Safety}

A general safety approach is to design the vehicle to be excessively cautious when uncertain situations occur, and to degrade gracefully when malfunctioning. The techniques presented for sensing the environment can be used to detect objects near the robot and humans coming too close to the robot. Specific techniques involving infrared detectors and cameras may also be used for the latter purpose.

Inclinometers measure the orientation of the gravity vector relative to the vehicle. These can be used to detect holes and steeps that would cause the robot to fall or turn over. In its simplest form, they can be implemented as mercury switches. More sophisticated types measure the tilt and skew of the vehicle in degrees by sophisticated combinations of accelerometers and gyroscopes. Inclinometers are essential in forest environment since they can prevent serious damage to the autonomous vehicle.

\section{Proposed system design}

A forest is an example of an unstructured environment, which changes during operations, and in which tasks cannot be completely programmed a priori. For these reasons, the classical hierarchical approach to building robots was replaced by a reactive approach, in which a set of reactive behavioural rules is used to produce a compound, yet still reactive, behaviour. However, the system discussed here is too complex to be realised by such reactive behaviours alone. Path planning and supervision of performance are examples of tasks that must have more intelligence to fulfil the requirements. The answer to this general problem in robotics is hybrid systems that combine hierarchical and reactive components (cf. Blackmore et al. [13]). In Murphy [52], an examination of different architectures is made. Orebäck and Christensen [61] compare three available hybrid architectures for mobile robots and present principles to guide in the design of new architectures. The design must aim at a performance, which is advantageous in the long-term, e.g., minimum risk of failure, optimal routes, and maximum utilisation [13]. Based on the requirements and techniques outlined in the previous Sections, a proposed system design is hereby presented.

\subsection{Hardware components}

The hardware has the following major parts:

- Sensors for stem identification, obstacle detection, localisation, stability, etc. Machine vision in combination with laser scanners are promising tools for target identification. The same techniques can be used for obstacle detection. However, radar is less affected by the climate, and should therefore also be considered for detection of obstacles. Promising localisation techniques are combinations of 
GPS and INS. Inclinometers should be used to monitor the tilt of the robot and thereby avoid dangerous slopes and holes. The exact choice of sensor techniques has to be based on rigorous field tests.

- Hardware for propulsion. Small legged machines have a better capability of handling rough terrain than small wheeled machines. However, there are drawbacks to legged propulsion, such as the need for an advanced motion control system. This speaks in favour of wheeled machines.

- Hardware for cutting. A promising technique is the shearing tool presented by Ligné et al. [47], since this tool snips the stems off. This method reduces the risk of thrown objects in comparison to rotating tools, which can cause damage to remaining trees and may be harmful to the operator and others.

- Control system. Computer for control and sensing. The system should also contain functionality for communication with operators for fault diagnosis and supervision.

\subsection{Software components}

The control system is the software responsible for task planning, selection of main-stems, sensor handling, propulsion, and cutting operations. The proposed software architecture for the vehicle follows the hybrid paradigm common in robotics [52]. The components in the proposed architecture have the following functions:

- The Mission planner is responsible for fulfilment of the overall goal. A plan is produced and sent to the Sequencer for execution. A general plan for cutting a subarea may be designed as follows:

1. Create a map of the trees and obstacles in the sub-area by using the sensors.

2. Select main-stems and targets for cutting (target-trees) on the map.

3. For each target-tree: execute the Target handling behaviour.

- The Sequencer takes a plan and executes the parts of the plan in sequence.

- The Cartographer is responsible for creation and maintenance of local maps for each sub-area. It communicates with the sensors and provides map info to the other parts of the system.

- The Resource manager determines and allocates suitable sensors for the current light and weather conditions.

- The Performance monitoring allows the vehicle to notice if it is making progress or if it has to be reset or if human help has to be called for. This module also performs overall safety tasks such as checking the robots' stability and detecting humans and animals within a certain distance from the robot.

The Target handling behaviour deals with the main task for the vehicle: moving to a target-tree and cut it. It can be described as a sequence of reactive behaviour coordinated by a finite state machine (FSM) [52]. An overview design is shown in Fig. 2. The three top circles denote the main sub behaviours Navigate, Identify and Cut. 
- Navigate is a behaviour composed of three parallel main activities: localisation of the vehicle, navigation to the target, obstacle detection and avoidance.

- Identify senses the target-tree after successful navigation. A decision is then taken whether the tree possesses the assumed properties for cutting.

- $C u t$ is an activity composed of a sequence of actions for gripping, cutting and handling the cut tree.

The FSM moves between the three sub behaviours depending on information provided by the sensors in the following way:

The Navigate behaviour continues until the input target is found. The control is then transferred to the Identify behaviour, which continues until an identification of the target-tree is available. Depending on the outcome of the identification, the control is transferred to either the Cutting behaviour or the Done state. The Done state is also activated if the Navigation or Identify behaviour runs into problems and fails. Once the Done state is reached, the control is transferred back to the $\mathrm{Se}$ quencer. The Sequencer then calls the Target behaviour again, now with a new targettree as argument.

All these behaviours are complex and will need extensive research and development before even a working prototype can be presented. It should be noted that the mission planner has to create and execute plans on a higher level as well, so the entire area is covered, and the overall goals of the cutting task are met. However, these issues are not discussed further in this paper.

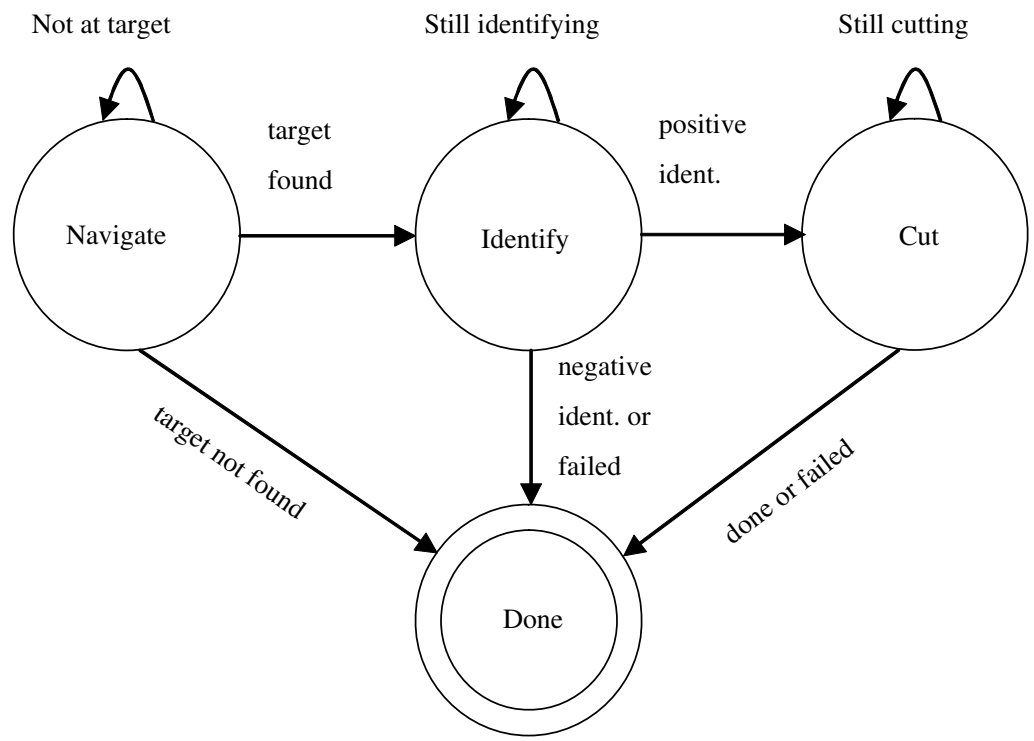

Fig. 2. Finite state machine with behaviours for the Target handling behaviour. The Navigate behaviour moves on to the Identify behaviour when a target-tree has been found. A positive identification moves the control to the $C u t$ behaviour, which is responsible for the actual felling of the tree. 


\section{Conclusions}

Obstacle avoidance and target identification are identified as the most difficult problems. The robot must be able to adapt to various requests from different landowners regarding, e.g., desired characteristics of main-stems, number of remaining stems, and percentage of deciduous trees. This makes identification and automatic selection of stems in cleaning a critical stage for a robot to become autonomous. Automation would remove personal variations, so the results becomes more uniform, and this stresses the importance of the selection of main-stems. The desirable results after cleaning must be represented in a way, by which a computer can accomplish satisfactory results in varying forest types.

Apart from the central issue of finding and selecting trees, all work tasks in cleaning must be described from a robot's perspective. These tasks include moving around in the unstructured and "hazardous" environment of a forest, cutting and felling trees, and treating the whole designated area without damaging remaining trees. The robot must also be able to be integrated in a silvicultural system at large, i.e., it must function and operate in organisations with people and other machinery. These are issues for the forestry research community in cooperation with robotics development researchers. Developing safe techniques for obstacle detection, localisation, and propulsion will be primarily tasks for robotics researchers, although forestry researchers must participate and explain the forest environment and its special hazards. Solutions from the multimedia and automotive industry, as well as agriculture are likely to be used to get cost-effective systems. Traditional forest machineries are used up to $3000 \mathrm{~h}$ per year, but a robot working autonomously can be theoretically working continuously, i.e., $8760 \mathrm{~h}$ per year. This indicates that productivity may be lower than it is with conventional machinery. However, transportation between sites, situations with faults and alarms, as well as maintenance decrease the productive time, but on the other hand, the costs of personnel can be cut in an automated system. The personnel could be given better opportunities to carefully plan, report, and evaluate the work, instead of directly controlling a machine.

\section{References}

[1] Andersson PO, Svensson S. Skogsvård i Norden -nuläge och framtidsbedömning (Silviculture in the Nordic countries - present situation and future outlook). Redogörelse nr. 8, Forskningsstiftelsen Skogsarbeten, Stockholm, Sweden; 1976. p. 23 [in Swedish with English summary]. ISSN: 0346-6671.

[2] Anon. Skogsvårdslagen: med tillämpningsanvisningar [Swedish Forestry Act: applicational instructions]. Stockholm (Sweden): National Board of Forestry; 1975. 54 pp. [in Swedish].

[3] Anon. Collins English dictionary. 3rd updated standard edition. Glasgow (UK): HarperCollins Publishers; 1995. ISBN: 000 470678-1.

[4] Anon. Statistical yearbook of forestry. Jönköping, (Sweden): Sveriges officiella statistik, National Board of Forestry; 1995. p. 245 [in Swedish with English summary]. ISBN: 91-88462-25-0.

[5] Anon. Röjning [Cleaning]. Falun (Sweden): StoraEnso Skog; 1999. p. 9, 12 [in Swedish].

[6] Anon. Skogsencyklopedin [The forest encyclopaedia]. Stockholm (Sweden): Sveriges Skogsvårdsförbund; 2000. p. 357, 389-90 [in Swedish]. ISBN: 91-7646-041-X. 
[7] Anon. Annual report. Pointe-Claire (Que., Canada): Forest Engineering Research Institute of Canada; 2001. p. 8. Available from: <www.feric.ca $>$.

[8] Anon. Australian centre for field robotics - 2001 annual report. Sydney (Australia): University of Sydney; 2001.

[9] Anon. Statistical yearbook of forestry. Sveriges officiella statistik, Jönköping (Sweden): National Board of Forestry; 2003. p. 118, 127, 237 [in Swedish with English summary]. ISBN: 91-88462-54-4.

[10] Berg H, Bäckström PO, Gustavsson R, Hägglund B. Några system för ungskogsröjning-en analys [Analysis of some systems for cleaning of young forest stands]. Redogörelse $\mathrm{Nr} 5$, Forskningsstiftelsen Skogsarbeten, Stockholm, Sweden; 1973. p. 12 [in Swedish]. ISSN: 0346-6671.

[11] Berg S. Terrain classification system for forestry work. Kista (Sweden): Forskningsstiftelsen Skogsarbeten; 1992. 28 pp. ISBN: 91-7614-078-4.

[12] Bergh C, Kennedy B, Matthies L, Johnson A. A compact, low power two-axis scanning laser rangefinder for mobile robots. In: The 7 th mechatronics forum international conference, Atlanta, Georgia, USA; 2000. 6 pp.

[13] Blackmore S, Fountas S, Have H. Proposed system architecture to enable behavioral control of an autonomous tractor. In: Zhang Q, editor. Automation technology for off-road equipment, Proceedings of the July 26-27, 2002 Conference, Chicago, IL, USA; 2002. p. 13-23. ASAE Publication Number 701P0502.

[14] Blackmore S, Have H, Fountas S. Specification of behavioural requirements for an autonomous tractor. In: Zhang Q, editor. Automation technology for off-road equipment, Proceedings of the July 26-27, 2002 Conference, Chicago, IL, USA; 2002. p. 33-42. ASAE Publication Number 701P0502.

[15] Brunberg B. Handledning i Röjning [Manual for cleaning]. Kista (Sweden): Forskningsstiftelsen Skogsarbeten; 1990. p. 6, 39-40 (In Swedish). ISBN: 91-7614-073-3.

[16] Borenstein J, Everett B, Feng L. Navigating mobile robots: systems and techniques. Wellesley (MA, USA): A.K. Peters Ltd.; 1996, 225 pp. ISBN 1-56881-058-X.

[17] Dunn SM, Liang T. Geometry guided segmentation. In: Casasent P, editor. Proceedings SPIE, vol. 1002, Intelligent robots and computer vision VII; 1989. p. 194. ISBN: 0-8194-0037-8.

[18] Durrant-Whyte H. A critical review of the state-of-the-art in autonomous land vehicle systems and technology. Albuquerque(NM) and Livermore(CA), USA: Sandia National Laboratories; 2001.p. 41.

[19] Eickhoff K. Beståndsval vid maskinell röjning [Stand selection when cleaning is made mechanical]. Resultat Nr. 3, Forskningsstiftelsen Skogsarbeten, Spånga (Sweden); 1987. 4 pp. [in Swedish]. ISSN: 0280-1884.

[20] Eliasson L, Lageson H, Valinger E. Influence on sapling height and temperature on damage to advanced regeneration. Forest Ecol Manage 2003;175(1-3):217-22.

[21] Erikson M, Vestlund K. Finding tree-stems in laser range images of young mixed stands to perform selective cleaning. In: Hyyppä J, Naesset E, Olsson H, Granqvist-Pahlén T, Reese H, editors. Proceedings of the scandlaser scientific workshop on airborne laser scanning forests, September 3-4, 2003, Umeå, Sweden. Working Paper 112, Swedish University of Agricultural Sciences, Umeå, Sweden; 2003. p. 244-50. ISSN: 1401-1204.

[22] Eriksson B. Snödjupsförhållanden i Sverige, säsongerna 1950/51-1979/80 (Snow conditions in Sweden during the seasons 1950/51-1979/80). Report no. 59, SMHI reports meteorology and climatology, SMHI, Norrköping, Sweden; 1990. p. 37-9 [in Swedish with English summary]. ISSN: 0347-2116.

[23] Everett HR. Sensors for mobile robots: theory and application. Wellesley (MA, USA): A.K. Peters; 1995. 528 pp. ISBN: 1-56881-048-2.

[24] Forsman P. Feature based registration of 3D perception data for indoor and outdoor map building. In: Halme A, Chatila R, Prassler E, editors. Proceedings of the 3rd international conference on field and service robotics, 11-13 June, Finland; 2001. p. 367-72. ISBN: 952-5183-13-0.

[25] García-Alegre MC, Ribeiro A, García-Pérez L, Martínez R, Guinea D, Pozo-Ruz A. Robot in agriculture tasks. In: 3ECPA-3 European conference on precision agriculture, Montpellier; France; 2001. 7 pp. ISBN: 2-900792-13-4.

[26] Gellerstedt S, Moberg L, Jansson CJ, Asplund C, Herlitz A. Automatiserad röjning, del 1. (Automated mechanical spacing of young stands of forest, Part 1). Research Note No. 4, Department 
of Forest Management and Products, Swedish University of Agricultural Sciences, Uppsala, Sweden; 1999 [in Swedish with English summary]. ISSN: 1403-9516.

[27] Gerrish JB, Fehr BW, Van Ee GR, Welch DP. Self-steering tractor guided by computer vision. Appl Eng Agric 1997;13(5):559-63.

[28] Gillet J, McCuaig R, Scherzinger B, Lithopoulos E. Tightly coupled inertial/GPS system for precision forestry surveys under canopy: test results. In: First international precision forestry symposium, June 17-20, 2001. Seattle (WA, USA): University of Washington; 2001.

[29] Gotthardsson N, Utvärdering av precision och noggranhet hos GPS-mottagare i skördarmiljö (Evaluation of precision and accuracy of GPS-recievers in a harvester environment). Students' reports No. 61, Forest technology, Swedish University of Agricultural Sciences, Umeå, Sweden; 2003. p. 17, 23-6 [in Swedish with English summary].

[30] Gustavsson R. Typbestånd i röjningsskog (Type stands for cleaning). Research Note No. 70, Department of Operational Efficiency, Royal College of Forestry, Garpenberg, Sweden; 1974. 54 pp. [in Swedish with English summary]. ISSN: 0585-332X.

[31] Halme A. Mobile robotics in unstructured environments - some advanced applications. In: Gellerstedt S, Asplund C, Wästerlund I, editors. 1996 Robotics with application to forestry. Research Note No. 285, Swedish University of Agricultural Sciences, Garpenberg, Sweden; 1996. p. 16-24. ISSN: 0282-2377.

[32] Halme A, Leppänen I, Ylönen S, Kettunen I. Workpartner - centaur-like service robot for outdoor applications. In: Halme A, Chatila R, Prassler E, editors. Proceedings of the 3rd international conference on field and service robotics, 11-13 June, 2001, Finland; 2001. p. 217-23. ISBN: 952-518313-0. See also: <www.automation.hut.fi/IMSRI >.

[33] Hagras H, Colley M, Callaghan V, Carr-West M. Online learning and adaptation of autonomous mobile robots for sustainable agriculture. Auton Robot 2002;13(1):37-52.

[34] Hague T, Marchant JA, Tillett ND. Ground based sensing systems for autonomous agricultural vehicles. Comput Electron Agric 2000;1-2(25):11-28.

[35] Hassel M, Hertzberg, J. Sensor fusion for localizing a mobile robot outside of buildings. In: Devy M, Lerasle F, editors. Proceedings of the 9th international symposium on intelligent robotic systems Toulouse, France; 2001. p. 477-84.

[36] Have H. Autonomous weeders for Christmas tree plantations-a feasibility study. Pesticides Research No. 59, Danish Environmental Protection Agency, Danish Ministry of the Environment, København, Denmark; 2002. 88 pp. ISBN: 87-7972-135-4.

[37] Hellström C. Mechanized cleaning in Sweden. Results No. 2, SkogForsk, Kista, Sweden; 1992.4 pp. ISSN: 1103-6222.

[38] Hellström T. Autonomous navigation for forest machines, a pre-study. Department of Computing Science, Umeå University, Umeå, Sweden; 2002. 60 pp., ISSN: 0348-0542.

[39] Högström T. Making a forest out of trees - Methods for segmenting range images of forest environments. In: Tele-commands for semi autonomous control in tele-robotics. Linköping studies in science and technology. Licentiate Thesis No. 624, Institute of Technology, Linköping University, Linköping, Sweden; 1997. ISSN: 0280-7971.

[40] Jansson J, Wästerlund I. The effect of traffic by light forest machinery on the growth of young Norway spruce trees. Scand J Forest Res 1999;14(6):581-8.

[41] Johansson T. Biologiska synpunkter vid maskinell röjning [Biological aspects in mechanized cleaning]. In: Kombinationsröjning [Combined cleaning]. Resultat Nr. 14, Forskningsstiftelsen Skogsarbeten, Uppsala, Sweden; 1991. p. 4 [in Swedish]. ISSN: 0280-1884.

[42] Karlsson H, Lundmark J, Sundkvist H, Wahlgren B, Jacobsson J, Johansson O. Röjningshandbok, virkeskvalité-ståndortsanpassning-naturvård [Cleaning manual, wood quality-site adaptation-nature conservation]. Stockholm (Sweden): AssiDomän Skog \& Trä; 1997. p. 11, 39-55 [in Swedish].

[43] Kourtz P. Autonomous forestry robots for brushing and thinning in young conifer stands: early Canadian experiences. In: Gellerstedt S, Asplund C, Wästerlund I, editors. Robotics with application to forestry. Uppsatser och resultat Nr. 285, Department of Operational Efficiency, Swedish University of Agricultural Sciences, Garpenberg, Sweden; 1996. p. 25-38. ISSN: 0282-2377. 
[44] Kurabyashi D, Asaman H. Navigation method by distributed map management for autonomous bush removal robot. In: Halme A, Chatila R, Prassler E, editors. Proceedings of the 3rd international conference on field and service robotics, 11-13 June, Finland; 2001. p. 361-66. ISBN: 952-5138-13-0.

[45] Löfgren B, Christensen HI, Alm H, Ohlsson K. Intelligenta kranar för utomhusbruk [Intelligent outdoor booms]. Work Report No. 454. SkogForsk, Uppsala, Sweden; 2000, p. 24-30 [in Swedish]. ISSN: 1404-305X.

[46] Ligné D. Sammanställning av patent och principer rörande röjning (Compilation of patents and principles concerning cleaning). Students' Reports No. 24, Forest Technology, Swedish University of Agricultural Sciences, Umeå, Sweden; 1999. p. 1-2 [in Swedish with English summary].

[47] Ligné, D. New technical and alternative silvicultural approaches to pre-commercial thinning. Umeå (Sweden): Acta Universitatis agriculturae Sueciae. Silvestria, Department of Silviculture, Swedish University of Agricultural Sciences, 2004. ISBN: 91-576-6715-2.

[48] Lindman J. Maskinell röjning-en presentation [Mechanical cleaning - a presentation]. Resultat Nr. 2, Forskningsstiftelsen Skogsarbeten, Spånga, Sweden; 1987. 4 pp. [in Swedish]. ISSN: 0280-1884.

[49] Marchant JA, Hague T, Tillett ND. Row-following accuracy of an autonomous vision-guided agricultural vehicle. Comput Electron Agric 1997;16(2):165-75.

[50] Martins-Filho LS, Prajoux R. Locomotion control of a four-legged robot embedding real-time reasoning in the force distribution. Robot Auton Syst 2000;32(4):219-35.

[51] Mattsson S, Westerberg D. Röjmaskiner i praktisk drift [Cleaning machines in operational use]. Resultat Nr. 5, SkogForsk, Uppsala; 1992. 4 pp. [in Swedish]. ISSN: 1103-4173.

[52] Murphy R. Introduction to AI robotics. Cambridge (MA, USA): MIT Press; 2000. 466 pp. ISBN 0262-13383-0.

[53] Noguchi N, Reid JF, Will J, Benson E, Stombaugh TS. Vehicle automation system based on multisensor integration. ASAE Paper 983111. St. Joseph, MI; 1998. UILU-ENG-98-7021.

[54] Normark E, Bergqvist G. Röjningshandledning [Cleaning manual]. Örnsköldsvik (Sweden): Holmen Skog; 2000. p. 4-7 [in Swedish].

[55] Nordfjell T. Små terrängmaskiner för skogsbruk, egenskaper och krav [Samll terrain machines for forestry, performance and requirements]. Uppsatser och Resultat nr 163, Department of Operational efficiency, Swedish University of Agricultural Sciences, Garpenberg, Sweden; 1989. p. 204-5 [in Swedish with English summary]. ISSN: 0282-2377.

[56] Nordfjell T. Studier av framkomlighet och lastbärande förmåga för små terrängfordon [Studies of mobility and load capacity of small terrain vehicles]. Uppsatser och Resultat nr 265, Department of Operational efficiency, Swedish University of Agricultural Sciences, Garpenberg, Sweden; 1994. p. 12-3 [in Swedish with English summary]. ISSN: 0282-2377.

[57] O'Connor M, Bell T, Elkaim G, Parkinson B. Automatic steering of farm vehicles using GPS. In: Proceedings of the third international conference on precision agriculture; Minneapolis, MA, USA; 1996. $10 \mathrm{pp}$.

[58] Ollis M. Perception algorithms for a harvesting robot. Carnegie Mellon University, Doctoral Dissertation, CMU-RI-TR-97-43; Pittsburgh, PA, USA; 1997. 96 pp.

[59] Ollis L, Stentz A. First results in vision-based crop-line tracking. In: 1996 Proceedings of the IEEE robotics an automation conference, Minneapolis, MN, USA; 1996. p 951-6.

[60] Ollis L, Stentz A. Vision-based perception for an automated harvester. In: Proceedings of IROS'97, Grenoble, France; 1997.

[61] Orebäck A, Christensen HI. Evaluation of architectures for mobile robotics. Auton Robot 2003;14(1):33-49.

[62] Petré E. Maskinell röjning med kranspetsmonterat aggregat (Mechanized cleaning with boommounted flail). Forskningsstiftelsen Skogsarbeten, Redogörelse no 4, Spånga, Sweden; 1984. p. 11. [in Swedish with English summary]. ISSN: 0346-6671.

[63] Pettersson B, Bäcke J. Röjningsundersökning 1997, Produktion-Miljö [Cleaning inventory 1997, yield-environment]. Meddelanden Nr 7, Swedish National Board of Forestry, Jönköping, Sweden; 1998. 18 pp. [in Swedish]. ISSN: 1100-0295. 
[64] Pilarski T, Happold M, Pangels H, Ollis L, Fitzpatrick K, Stentz A. The demeter system for automated harvesting. In: American nuclear society 8 th international topical meeting on robotics and remote systems, Pittsburgh, PA, USA; 1999. 10 pp.

[65] Ratner D, McKerrow P. Navigating an outdoor robot along continuous landmarks with ultrasonic sensing. Robot Auton Syst 2003;45(2):73-82.

[66] Reid JF. Precision guidance of agricultural vehicles. SME Meeting, Sapporo, Japan, UILU-ENG7031; 1998.

[67] Ryans M, St-Amour M. Mechanized systems for early stand tending in central and eastern Canada. Report No. 2, SkogForsk, Uppsala, Sweden; 1996. p. 189-98. ISSN: 1103-6648.

[68] Simmons R, Henriksen L, Chrisman L, Whelan G. Obstacle avoidance and safeguarding for a lunar rover. In: Proceedings AIAA forum on advanced developments in space robotics, Madison WI, USA August; 1996. 9 pp.

[69] Singh S. The state of the art in automation of earthmoving. ASCE J Aerospace Eng 1997;10(4):179-88.

[70] Stentz A. Robotic technologies for outdoor industrial vehicles. In: Proceedings of SPIE AeroSense, Conference on unmanned vehicles, Orlando, Florida, USA; 2001.

[71] Suomela J, Kuusela J, Halme A. Millimeter wave radar for close terrain mapping of an intelligent autonomous vehicle. In: 2nd IFAC conference on intelligent autonomous vehicles, Helsinki University of Technology, Espoo, Finland; 1995. p. 349-54.

[72] Söderström V. Ekonomisk skogsproduktion. D. 3, Beståndsvård [Economical forest production. D3 Stand tending]. LT, Stockholm, Sweden; 1980. 216 pp. [in Swedish]. ISBN: 91-36-01486-9.

[73] Tanaka T, Ohwi J, Litvintseva LV, Yamafuji K, Ulyanov SV. Soft computing algorithms for intelligent control of mobile robot for specific use. Part 2: Path planning, navigation and technology operations. Soft Comput 1997;1(2):99-106.

[74] Tarp-Johansen MJ. Locating individual trees in even-aged oak stands by digital image processing of aerial photographs. PhD Thesis, Royal Veterinary and Agricultural University, Copenhagen, Denmark; 2001. 158 pp.

[75] Vestlund K. Autonom röjning, förutsättningar (Autonomous cleaning of young forest stands, conditions). Report No. 12, Department of Forest Management, Swedish University of Agricultural Sciences, Uppsala, Sweden; 2001. 39 pp. [in Swedish with English summary]. ISSN: 1403-9516.

[76] Vestlund K. Redovisning av intervjuer med tre personer som utför ungskogsröjning (Report of interviews with three persons performing cleaning and spacing in young forest stands). Report No. 14, Department of Forest Management, Swedish University of Agricultural Sciences, Uppsala, Sweden; 2001. 15 pp. [in Swedish with English summary]. ISSN: 1403-9516.

[77] Wästerlund I. Mark- och beståndsskador efter mekaniserad röjning (Damage to the ground and the stand after mechanized cleaning). Uppsatser och Resultat nr 193, Department of Operational Efficiency, Swedish University of Agricultural Sciences, Umeå, Sweden; 1990. p. 37 [in Swedish with English summary]. ISBN: 91-576-4239-7.

[78] Yahja A, Singh S, Stentz A. An efficient on-line path planner for outdoor mobile robots. Robot Auton Syst 2000;32(2-3):129-43.

[79] Zhang Q, Reid JF, Noguchi N. Agricultural vehicle navigation using multiple guidance sensors. In: Proceedings of the international conference on field and service robotics, August 29-31, UILU-ENG99-7013, The Robotics Institute at Carnige Mellon University, Pittsburg, PA, USA; 1999. 